\title{
Brief anatomical reminder of the spinal column
}

Keywords: anatomy, spine, vertebral column

\section{Introduction}

The spine is a structure that provides support to the entire body, in addition to fulfilling the function of protecting the spinal cord and spinal nerves, assisting the posture and locomotion of the human body. That is why remembering the anatomy of the spine represents an advantage to avoid injuries and to adequately maximize its performance in the development of any sport or work activity.

In addition due to our lifestyle and throughout the age, the spine will undergo different osteodegenerative changes, can generate different symptoms such as back pain and radiculopathy, which are quite frequent among the population, being able to present from teenagers to adulthood, representing one of important cause of disability.

\section{Anatomy}

The vertebral column is composed of 7 cervical, 12 thoracic, 5 lumbar and 5 sacral vertebrae with 5 fused coccygeal bones; all the cervical, thoracic and lumbar ones have the same morphology except for the atlas $(\mathrm{C} 1)$ and the axis $(\mathrm{C} 2) ;{ }^{1}$ which serves to hold the skull and to make movements of the head with adequate stability. ${ }^{2}$ Between the vertebrae there are spaces called foramina through which the spinal nerves that fulfill a sensory and motor function originate. ${ }^{3}$

Between the vertebral bodies is the intervertebral disc (Figure $1 \& 2$ ), a cartilaginous structure that fulfills the double function of giving primary support to the spine and sufficient elasticity to allow movements of the spine, ${ }^{1}$ which normally has a biconvex shape. ${ }^{4}$ This disc is composed of central part by a nucleus pulposus (containing up to $88 \%$ of water in young and healthy discs ${ }^{1}$ ) that is externally contained by a fibrous annulus. ${ }^{3}$

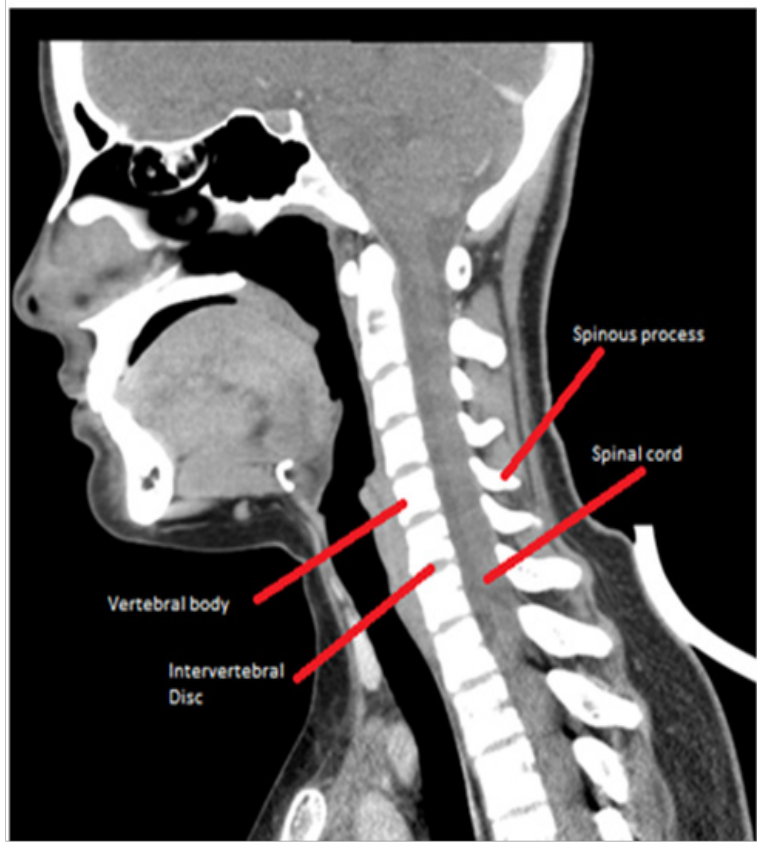

Figure I Sagital view-Cervical computed tomography.
Volume 3 Issue 2 - 2019

\section{María Ameyali Pérez-Huitrón, Azucena} Moreno-Sánchez

Department of Radiology Centro Médico Nacional “La Raza, México

Correspondence: María Ameyali Pérez-Huitrón, Departmen of Radiology Centro Médico Nacional “La Raza, México, Email ameyali_ph@hotmail.com

Received: June 04, 2019| Published: June 10,2019

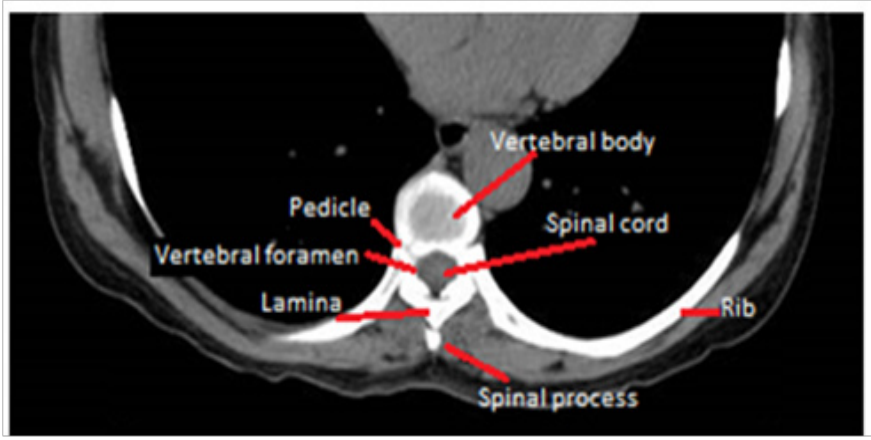

Figure 2 Axial view-Parts of thoracic vertebrae.

In addition many ligaments participate in the support and movement of the spine, some are more important than others. ${ }^{1}$ The posterior longitudinal ligament is one of them and is found from the axis to the sacrum, constituting the anterior part of the spinal canal; the open space between the posterior longitudinal ligament and the vertebral body is the anterior epidural space, which is important in disc herniation.

Other ligaments that contribute to the stabilization of the spine include the anterior longitudinal ligament, the ligamentum nuchae from the occiput to the cervical vertebra, the infraspinous ligaments, and the supraspinous ligaments. ${ }^{1}$

There are several risk factors that have been shown to affect pain in both the neck and lower back, being important to reduce or keep them controlled for an adequate quality of life, such as inappropriate postures, psychosocial factor, obesity, smoking, drug abuse, since in addition some risk factors are non-modifiable such as increasing age, leg length differences, anthropometric status.

\section{Acknowledgements}

None.

\section{Conflicts of interest}

The authors declare there is no conflict of interest.

\section{References}

1. Devereaux MW. Anatomy and examination of the spine. Neurol Clin. 2007;25(2):331-351. 
2. Bogduk N. Functional anatomy of the spine. Handb Clin Neurol. 2016;136:675-688.

3. Pohl M, Back T, Leimert M, et al. Cervical Radiculopathy. Aktuelle Neurol. 2018;45(5):349-369.
4. Sánchez Pérez M, Gil Sierra A, Sánchez Martín A, et al. Nomenclatura estandarizada de la patología discal. Radiologia. 2012;54(6):503-512. 